\title{
UROPATHOGENS AND THEIR ANTIMICROBIAL SUSCEPTIBILITY PATTERN IN A TERTIARY CARE HOSPITAL
}

Yashavanth R, Ronald R, Anita K, Narendra N, Faseela T

1. Assistant Professor, Department of Microbiology, AJIMS, Kuntikana, Bejai, Mangalore.

2. Professor and HOD, Department of Microbiology, AJIMS, Kuntikana, Bejai, Mangalore.

3. Associate Professor, Department of Microbiology, AJIMS, Kuntikana, Bejai, Mangalore.

4. Professor, Department of Microbiology, AJIMS, Kuntikana, Bejai, Mangalore.

5. Lecturer, Department of Microbiology, AJIMS, Kuntikana, Bejai, Mangalore.

\section{CORRESPONDING AUTHOR}

Dr. Yashavanth Kumar Rai,

Assistant Professor, Dept Microbiology,

AJIMS, Mangalore,

E-mail: dryashwanthrai@gmail.com,

Ph: 00919986297656.

ABSTRACT: BACKGROUND: Urinary tract infections (UTI) are one of the most common infectious diseases in humans. Antimicrobial drug resistance is one of the major threats due to wide spread use of inappropriate and empirical antibiotic therapy. The present study highlights the organisms causing UTI and their antimicrobial susceptibility pattern. MATERIALS AND METHODS: A total number of 1266 urine samples were analysed in a tertiary care hospital. Urine samples were processed by calibrated loop technique, delivering $0.001 \mathrm{ml}$ of urine and plated on to MacConkey's and Cysteine Lactose Electrolyte Deficient (CLED) agar plates and incubated at $37^{\circ} \mathrm{C}$ overnight. Appropriate biochemical tests were carried out to identify the uropathogens. Antimicrobial susceptibility of the isolates was determined against various antimicrobial agents. RESULTS: Among this, 332(26.22\%) culture positive isolates were identified and their antimicrobial susceptibility patterns were analysed. Among the culture positive isolates, Escherichia coli (54.21\%)was the most common pathogen followed by Klebsiella spp (22.89\%) and Enterococcus spp (6.92\%). Majority of these isolates were resistant to Cotrimoxazole, Amoxycillin/ Clavulanic acid, Piperacillin, Norfloxacin, Ciprofloxacin and also to third generation cephalosporins. Escherichia coli isolates showed good sensitivity towards Amikacin, Piperacillin/ Tazobactum, Nitrofurantoin and Meropenem. Klebsiella isolates showed good sensitivity towards Amikacin, Levofloxacin, Piperacillin/ Tazobactum and Meropenem. Staphylococcus aureus and Enterococcus spp showed good response towards Linezolid, Netilmicin, Vancomycin and Teicoplanin. There is also increase in incidence of Extended Spectrum Beta Lactamase (ESBL) production among Escherichia coli (65\%) and Klebsiella spp (55\%). Study also showed that females (67.17\%) are more vulnerable to urinary tract infections than males (32.83\%). CONCLUSION: Due to excessive use of antimicrobials for all sorts of infections, uropathogens are increasingly showing resistance to antibiotics. Knowledge of uropathogens and their antimicrobial susceptibility pattern in a geographical region will help in appropriate and judicious antibiotic usage in a health care setup.

KEYWORDS: Urinary Tract Infection, Antibiotic Susceptibility Pattern, ESBL

INTRODUCTION: Urinary tract infections (UTI) are one of the most common infectious diseases in humans. Antimicrobial drug resistance is one of the major global threats. ${ }^{1}$ Antibiotics are usually given empirically before the laboratory reports of urine cultures are available. 
Inappropriate and empirical usage of wide spectrum of antibiotics, insufficient hygiene, immunosuppression and prolonged hospitalisation are some of the major etiological factors that increase the chances of UTIs. ${ }^{2}$ Wide spectrum of organisms are implicated in its aetiology, the most common being Escherichia coli and Klebsiella spp followed by Gram positive organisms. ${ }^{3}$

Gram negative bacilli shows high incidence of resistance against Cotrimoxazole, Norfloxacin, Piperacillin, Fluoroquinolones and third generation cephalosporins. ${ }^{4,5} \mathrm{Gram}$ positive cocci shows high incidence of resistance against Ampicillin, Amoxycillin, Penicillin, Amoxycillin/ Clavulanic acid and Erythromycin. Antibiotic susceptibility pattern of uropathogens vary according to the geographical and regional locations. The knowledge about uropathogens and their resistance patterns is important for appropriate therapy and also for prevention of resistance amongst the microbes. In this context present study was carried out to know the common uropathogens and their susceptibility pattern in a tertiary care hospital.

MATERIALS AND METHODS: A total of 1266 clean catch midstream urine samples were collected in a sterile container from both outpatients and inpatients in our hospital during study period (January 2010 - December 2011). Urine samples were transported immediately to microbiology laboratory and processed. Urine samples were processed by calibrated loop technique delivering $0.001 \mathrm{ml}$ of urine and plated on to MacConkey's and Cysteine Lactose Electrolyte Deficient (CLED) agar plates and incubated at $37^{\circ} \mathrm{C}$ overnight. For Gram negative bacilli more than $10^{5}$ colonies per $\mathrm{ml}$ and for Gram positive cocci $10^{3}-10^{5}$ colonies per $\mathrm{ml}$ of single organism were considered significant. Uropathogens were further identified by the morphological and biochemical characteristics. ${ }^{6}$

Antimicrobial susceptibility of the isolates was determined against various antimicrobial agents by Kirby Bauer disk diffusion method on Muller Hinton agar plates according to Clinical and Laboratory Standard Institute(CLSI) guidelines. ${ }^{7}$ Antibiotics for Gram negative bacilli

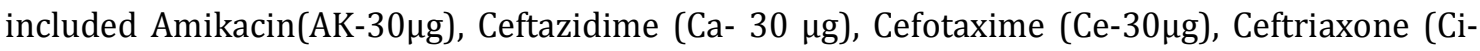

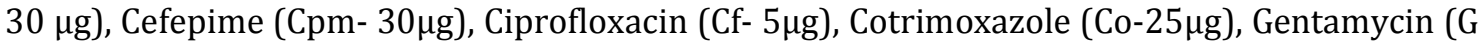

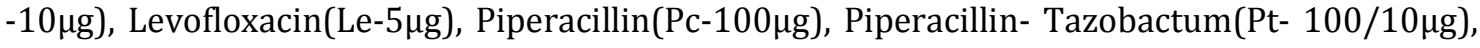

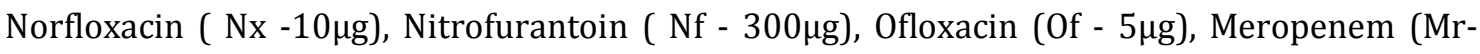

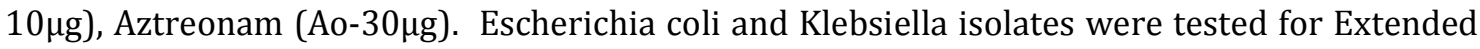
Spectrum Beta Lactamase (ESBL) production by double disk diffusion method with Ceftazidime and Ceftazidime Clavulanic acid combination as recommended by CLSI guidelines. ${ }^{7}{ }^{8}$ Escherichia coli ATCC 25922 and Klebsiella pneumoniae ATCC 700603 strains were used as controls.

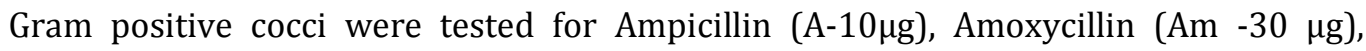

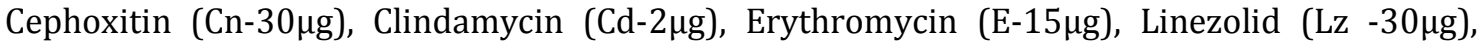

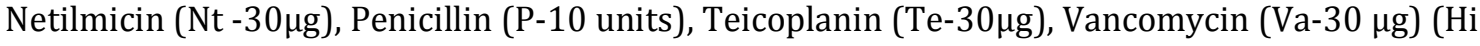
Media, Mumbai). Staphylococcus aureus ATCC 25923 and Enterococcus faecalis ATCC 29212 strains were used as controls. The results were recorded and interpreted according to CLSI guidelines.

RESULTS: Out of 1266 urine samples, 332(26.22\%) were found to be culture positive isolates. Among 332 culture positive isolates, 223 (67.17\%) were obtained from females and $109(32.83 \%)$ were obtained from males as shown in Table1. The highest isolation rates was found in 20 - 69 age group as shown in Table 2. 
Escherichia coli(54.21\%) was the predominant uropathogen, followed by Klebsiella $\operatorname{spp}(22.89 \%)$, Enterococcus $\operatorname{spp}(6.92 \%)$, Staphylococcus aureus (5.21\%), Acinetobacter spp (3.31\%) and Citrobacter spp (3.01\%) as shown in Table 3. The antibiotic resistance among uropathogens to the agents that had been recommended as the first line therapy is on rise. The Gram negative bacilli which were isolated showed high degree resistance pattern against Cotrimoxazole, Norfloxacin, Piperacillin, Ciprofloxacin and third generation cephalosporins. Escherichia coli isolates showed higher sensitivity towards Amikacin (91.18\%), Nitrofurantoin (90.52\%), Piperacillin- Tazobactum (96.44\%) and Meropenem (100\%). Klebsiella isolates showed good response towards Amikacin (92.61\%), Levofloxacin (90\%), PiperacillinTazobactum (95\%), Meropenem (100\%) as shown in Table 4. ESBL production among Escherichia coli isolates were $65 \%$ and Klebsiella isolates, 55\%. Enterococcus spp showed good response towards Linezolid (100\%), Vancomycin (100\%), and Teicoplanin (87.5\%). Staphylococcus aureus showed good response towards Linezolid (88.1\%), Netilmicin (87.5\%), Vancomycin (100\%), Teicoplanin (100\%), as shown in Table 5.

DISCUSSION: The changing trends in the aetiopathogenesis of urinary tract infections and increasing antimicrobial drug resistance are a matter of concern. Urethral catheterisation and instrumentation related UTI is the most common nosocomial infection. ${ }^{9}$ Catheter related UTI increases morbidity, mortality and also cost of treatment for patients in a health care setup. ${ }^{10}$ The indiscriminate, inadequate usage of antibiotics has contributed to the emergence of resistance strains. ${ }^{11}$ Urine culture sensitivity is routinely done in suspected cases of UTI and empirical therapy should be started immediately and modified if required once the report of urine culture sensitivity is available. ${ }^{12,13}$

The present study shows the pathogens causing UTIs and their antibiotic susceptibility pattern. Escherichia coli was the predominant pathogen followed by Klebsiella spp and Gram positive cocci. This study is in concordance with the studies done by Manjunath et al, ${ }^{1}$ and Shigemura et al. ${ }^{7}$ Our study shows that females (67.17\%) are more vulnerable to UTIs than males (32.83\%), which is similar to previous studies done by Manjunath et al, ${ }^{1}$ and Dash et al. ${ }^{14}$ Females are more prone to UTIs probably due to their short urethra and physiological changes. Antimicrobial resistance of different uropathogens is one of the barricades that can interfere with an effective treatment. The present study indicates different antimicrobial susceptibility pattern among uropathogens. The broad spectrum activity of Fluoroquinolones and third generation Cephalosporin has made them therapeutic options for UTIs. The organisms which belonged to Enterobacteriaceae family, showed high degree of resistance towards Cotrimoxazole, Fluoroquinolones and third generation Cephalosporin, but these isolates showed good response against antibiotics like Amikacin, Nitrofurantoin, Piperacillin Tazobactum and Meropenem. This finding is similar to the studies done by Manjunath et al, ${ }^{1}$ and Shigemura et al.7 Our study also shows increase in ESBL producing strains among Escherichia coli (65\%) and Klebsiella spp (55\%), which is similar to the results of the studies done by Shiju et al,8and Shukla et al. ${ }^{15}$ ESBL producing organisms pose a major problem in clinical therapeutics, so there is a need for judicious use of antimicrobial agents and their continuous Invitro monitoring should be carried out, so that misuse of extended spectrum cephalosporins can be avoided. Gram positive cocci showed good susceptibility patterns towards Netilmicin, Linezolid, Vancomycin and Teicoplanin.

This study furnishes the much needed information on the common uropathogens and their antibiotic susceptibility pattern in our region. In view of the emerging drug resistance 
among uropathogens, therapy should be commenced after the culture and sensitivity has been performed. This would, not only help in the proper use of antibiotics but also prevent further development of bacterial drug resistance in community as well as in hospitals.

Table 1: Sex- wise distribution of UTI

\begin{tabular}{|l|l|}
\hline GENDER & Number of Isolates \\
\hline Male & $109(32.83 \%)$ \\
\hline Female & $223(67.17 \%)$ \\
\hline
\end{tabular}

Table 2: Age-wise distributions of uropathogens

\begin{tabular}{|l|l|l|l|}
\hline \multicolumn{1}{|c|}{ Age group } & \multicolumn{1}{c|}{ Male } & \multicolumn{1}{c|}{ Female } & \multicolumn{1}{c|}{ Total } \\
\hline $0-9$ & 3 & 18 & 21 \\
\hline $10-19$ & 10 & 35 & 45 \\
\hline $20-29$ & 15 & 58 & 73 \\
\hline $30-39$ & 16 & 36 & 52 \\
\hline $40-49$ & 23 & 23 & 46 \\
\hline $50-59$ & 13 & 23 & 36 \\
\hline $60-69$ & 23 & 20 & 43 \\
\hline $70-79$ & 3 & 8 & 11 \\
\hline $80-89$ & 3 & 2 & 5 \\
\hline
\end{tabular}

Table 3: Clinical strains isolated from urine samples.

\begin{tabular}{|l|l|l|}
\hline \multicolumn{1}{|c|}{ Uropathogens } & \multicolumn{1}{c|}{ No. of isolates } & \multicolumn{1}{c|}{ Percentage } \\
\hline Escherichia coli & 180 & $54.21 \%$ \\
\hline Klebsiella spp & 76 & $22.89 \%$ \\
\hline Acinetobacter spp & 11 & $3.31 \%$ \\
\hline Citrobacter spp & 10 & $3.01 \%$ \\
\hline Pseudomonas spp & 8 & $2.40 \%$ \\
\hline Provedencia spp & 4 & $1.20 \%$ \\
\hline Proteus mirabilis & 2 & $0.60 \%$ \\
\hline Enterobacter spp & 1 & $0.30 \%$ \\
\hline Enterococcus spp & 23 & $6.92 \%$ \\
\hline Staphylococcus aureus & 17 & $5.12 \%$ \\
\hline
\end{tabular}

Journal of Evolution of Medical and Dental Sciences/Volume1/ Issue4/October - 2012 Page 470 
Table 4: Antibiotic Susceptibility pattern(\% sensitivity): Gram negative bacilli.

\begin{tabular}{|c|c|c|c|c|c|c|c|c|c|c|c|c|c|c|c|c|}
\hline $\begin{array}{l}\text { Uropa } \\
\text { thogen }\end{array}$ & $\mathrm{Ak}$ & Ао & $\mathrm{Ca}$ & $\mathrm{Ce}$ & $\mathrm{Ci}$ & $\mathrm{Cpm}$ & $\mathrm{Cf}$ & Co & $\mathrm{G}$ & Le & $\mathrm{Mr}$ & $\mathrm{Nx}$ & $\mathrm{Nf}$ & Of & $\mathrm{Pc}$ & $\mathrm{Pt}$ \\
\hline E.coli & 91.18 & ND & 36.99 & 33.38 & 32.34 & 35.88 & 31.20 & 28.31 & 58.67 & $\begin{array}{l}60.9 \\
4 \\
\end{array}$ & 100 & $\begin{array}{l}23.7 \\
7 \\
\end{array}$ & $\begin{array}{l}90.5 \\
2 \\
\end{array}$ & 53.47 & $\begin{array}{l}23 . \\
74\end{array}$ & 96.44 \\
\hline $\begin{array}{l}\text { Klebsi } \\
\text { ella } \\
\text { Spp }\end{array}$ & 92.61 & ND & 46.89 & 39.64 & 41.3 & 49.51 & 53.75 & 49.61 & 68.35 & 90 & 100 & $\begin{array}{l}50.6 \\
9\end{array}$ & 70 & 43.18 & $\begin{array}{l}29 . \\
11\end{array}$ & 95 \\
\hline $\begin{array}{l}\text { Acinet } \\
\text { obacte } \\
\mathrm{r} \\
\mathrm{spp}\end{array}$ & 83.33 & ND & 71.42 & 66.66 & 66.66 & ND & 66.66 & 50 & 70 & 100 & 81.81 & 75 & ND & 50 & 50 & 81.81 \\
\hline $\begin{array}{l}\text { Citrob } \\
\text { acter } \\
\text { Spp }\end{array}$ & 79.16 & ND & 65 & 45 & 66.66 & 40 & 79.16 & 55 & 73.33 & 75 & 100 & 60 & 70.8 & 70 & 40 & 87.5 \\
\hline $\begin{array}{l}\text { Proteu } \\
\text { s } \\
\text { Spp } \\
\end{array}$ & 100 & ND & 50 & 50 & 50 & 50 & 50 & 50 & ND & 100 & 100 & 50 & 100 & 50 & ND & 100 \\
\hline $\begin{array}{l}\text { Pseud } \\
\text { omona } \\
\text { s } \\
\text { Spp } \\
\end{array}$ & 50 & $\begin{array}{l}37 . \\
5\end{array}$ & 50 & 50 & 37.5 & ND & 37.5 & 37.5 & ND & 50 & 75 & 50 & ND & 37.5 & $\begin{array}{l}62 . \\
5\end{array}$ & 87.5 \\
\hline $\begin{array}{l}\text { Provid } \\
\text { encia } \\
\text { Spp }\end{array}$ & 100 & ND & 50 & 50 & 50 & ND & 50 & 25 & ND & 75 & 100 & 50 & 75 & 50 & 50 & 100 \\
\hline $\begin{array}{l}\text { Entero } \\
\text { bacter } \\
\text { spp }\end{array}$ & 100 & ND & - & - & - & ND & - & - & ND & 100 & 100 & - & 100 & - & - & 100 \\
\hline
\end{tabular}

Table5: Antibiotic Susceptibility pattern(\% sensitivity): Gram positive cocci

\begin{tabular}{|l|l|l|l|l|l|l|l|l|l|l|l|l|l|l|l|}
\hline & $\mathrm{A}$ & $\mathrm{Am}$ & $\mathrm{Ac}$ & $\mathrm{Cd}$ & $\mathrm{Cz}$ & $\mathrm{Cn}$ & $\mathrm{E}$ & $\mathrm{G}$ & $\mathrm{Lz}$ & $\mathrm{Nt}$ & $\mathrm{Nx}$ & $\mathrm{Nf}$ & $\mathrm{P}$ & Va & Te \\
\cline { 2 - 13 } \\
\cline { 2 - 11 }
\end{tabular}

*ND-NOT DONE.

\section{REFERENCES:}

1. Manjunath GN, Prakash R, Vamseedhar A, Kiran S. Changing trends in the spectrum of antimicrobial drug resistance pattern of uropathogens isolated from hospitals and 
community patients with urinary tract infections in Tumkur and Bangalore. Int J Biol MedRes 2011; 2(2):504-7.

2. Sweih NA, Jamaal W,Rotimi VO. Spectrum and antibiotic resistance of uropathogensisolated from hospital and community patients with urinary tract infections in two largehospitals in Kuwait. MedPrincPract2005;14:401-7.

3. Azad UK, Mohd SZ. Multidrug resistance pattern inurinary tract infection patients in Aligarh. Bio Med Res 2006;17(3):179 -81.

4. De Francesco MA, Ravizzola G, Peroni L,Negrini R, Manca N. Urinary tract infections inBrescia, Italy.Etiology of uropathogens and antimicrobial resistance of common uropathogen. Med SciMonit 2007;13(6):136-44.

5. Forbes BA,Sahm DF, Weissfeld AS. Overview of bacterial identification methods and strategies. Baliley and Scott's Diagnostic Microbiology,12th ed., chapter 13. St.Louis: Mosby; 2007.-.216-47.

6. Clinical and Laboratory Standards Institute. Performance standards for

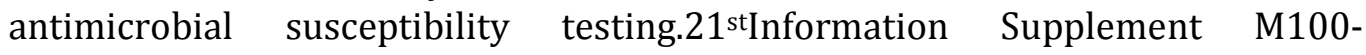
S21.Wayne,PA, USA: Clinical and Laboratory Standards Institute,2011.

7. Shigemura K, Arakawa S, Tanaka K, Fujisawa M. Clinical investigation of isolated bacteria from urinary tracts of hospitalized patients and their susceptibilities to antibiotics. J Infect Chemother2009;15:18-22.

8. Shiju MP, Yashavanth R, Narendra N. Detection of extended spectrum betalactamaseproduction and multidrug resistance in clinical isolates of E.coli and K.pneumoniaein Mangalore. J ClinDiagn Res 2010; 4(3): 2442-45.

9. Stark RP, Maki DG. Bacteriuria in a catheterized patient. N Eng J Med 1984; 311:560-64.

10. Kunin CM, Douthitt S, Dancing J, Anderson J, Moeschberger M.The association betweenthe use of urinary catheters and morbidity and mortality among elderly patients in a nursinghome.Am J Epidemiol 1992;135(3):291-301.

11. Gruneberg GN. Antibiotic sensitivities of urinary pathogens,1971 - 1982.J AntimicrobChemother 1984;14:17-23.

12. Farrell DJ, Morrissey I, De Rubies D, Robbins M, Felmingham D. UK multicentre study of the antimicrobial susceptibility of bacterial pathogens causing urinary tract infection. J Infect 2003;46(2):94-100.

13. Gupta V, Yadav A, Joshi RM. Antibiotic resistance pattern in uropathogens. Indian J Med Microbiol 2002;20:96-98.

14. Dash N, Al-Zarouni, Al-Kous, Al-Shehhi F, Al-Najjar J, Senok A et al. Distribution and resistance trends of community associated urinary tract pathogens in Sharjah, UAE.Microbiology Insights 2008;1:41-45.

15. Shukla I, Tiwari R, Agarwal M, Prevalence of extended spectrum beta lactamase producingKlebsiellapneumoniae in a tertiary care hospital. Indian J Med Microbial 2004; 22:87-91. 